Western University Scholarship@Western

1974

\title{
Structural Characteristics of Canada's Pattern of Trade
}

H. G. Baumann

Follow this and additional works at: https://ir.lib.uwo.ca/economicsresrpt

Part of the Economics Commons

Citation of this paper:

Baumann, H. G.. "Structural Characteristics of Canada's Pattern of Trade." Department of Economics Research Reports, 7401. London, ON: Department of Economics, University of Western Ontario (1974). 
Research Report 7401

\section{STRUCTURAL CHARACTERISTICS OF}

CANADA'S PATTERN OF TRADE

by

H. G. Baumann

February 1974 
Structural Characteristics of Canada's Pattern of Trade*

\section{A. Introduction}

Ever since the surprising discovery by Leontief that a representative bundle of U.S. exports required a lesser amount of capital than a representative bundle of U.S. imports, there has been a renewed interest in the determinants of the pattern of trade. ${ }^{1}$ The Heckscher-Ohlin theory, which in its purest form suggested that the capital abundant country would export the capital intensive commodity and the labour abundant country would export the labour intensive commodity, has been modified to take into account the existence of other factors of production such as human capital (education) and natural resources. In addition, some researchers have suggested that the entire $\mathrm{H}-\mathrm{O}$ apparatus be scrapped, and have developed theories and presented empirical evidence which stress the role of the technological factor in determining trade patterns. (Posner, 1961; Vernon, 1966; Finger 1973) When the literature on the effect of different tastes, tariffs and other distortions, transportation and information costs, etc. is added, it becomes apparent that a multi-dimensional explanation of the pattern of trade has now become necessary.

In the present paper, an attempt will be made to evaluate the empirical validity of the various hypotheses being put forth on the basis of data on patterns of bilateral trade between Canada and the United States. Certain structural characteristics (representing the empirical content of the various theories) of a sample of sixty-seven 3-digit Canadian industries will be related to the ratio of their imports from the U.S. over total Canadian shipments and the ratio of their exports to the U.S. over total Canadian shipments. In this way, it is hoped that something can be said about the fundamental 
challenges posed by recent work on the Heckscher-Oh1in and Ricardian theories. Thus, if physical capital and homogeneous labour do: not provide the complete picture what other factors are important? In the case of the Ricardian theory, one would like to know the causes of comparative cost differences given that intercountry efficiency differences for the same industry appear to be a fact of life. (Stern, 1973, 14) This particular line of inquiry can lead into the world of technology gaps and product cycles although their originators might emphasize the complete novelty of their theories.

Although the paper relies to some extent on data developed by Hufbauer (1970) and Baldwin (1971), as well as Wilkinson's (1968) methodology, there are nevertheless, certain points of novelty. Thus, an attempt will be made to determine which theory, neo-technology or neo-factor proportions, provides the best explanation of Canada's pattern of trade. $^{2}$ Moreover, the implication for the empirical results of using U.S. or Canadian coefficients will be evaluated. Finally, there are certain features of the Canadian economy which require careful consideration. These include the existence of diseconomies of scale, on both the plant and firm level, the abundance of certain natural resources and the great-extent of foreign direct investment. The effect of these factors on the pattern of Canada's trade can be illuminated by the introduction of the appropriate explanatory variables. 
B. The Choice of Dependent Variable

It is not unfair to say that there have been almost as many variations in the dependent variable as there have been studies on the determinants of the pattern of trade. The most obvious variable is the dollar value of total exports or imports of a sample of SITC commodity groups or their equivalent SIC industries in a particular year. ${ }^{3}$ The major difficulty with this approach is the inappropriateness of having the size of the industry affecting the magnitude of the dependent variable, and hence, some form of scaling is called for. The most popular method of scaling has been to divide industry exports or imports by total trade (Branson, 1972) i.e., exports plus imports, and this technique certainly minimizes the data problems although it has the undesirable effect that changes in exports (or imports) affect the both the numerator and the denominator in a very direct way, and previous research has shown that the pattern of exports and imports is influenced by different factors (Finger, 1973, 13). One alternative is to relate exports or imports to industry output or shipments, and this approach was followed in the present study since it has the added advantages of facilitating interpretation, and comparing the results with those obtained by Wildinson $(1968,146-49)$.

An entirely different method of scaling involves dividing a particular country's. exports for a given industry by total world exports for that same industry (Weiser and Jay, 1972). In general, the data work is made less onerous by taking a selected list of countries, usually the industrialized countries, which has the additional advantage that these countries tend to be homogeneous. An obvious problem is that the countries are not of equal size, but this method of scaling can be justified when an explanation for industry 
export performance is being sought. Incidentally, it is apparent that this dependent variable leads to a better fit or $\mathrm{R}^{2}$ when compared with those previously mentioned becuase it implicitly corrects for those resistance variables which affect the trading propensity of industries. 4

A related problem involves the question on whether to use exports, imports or net exports i.e., exports minus imports in the numerator of the dependent variable. Since it has been established that the determinants of the pattern of exports and imports may differ, it would appear advisable to use the gross as opposed to the net measure. However, this choice depends on the problem at hand since for any discussion of the effect of trade policy on the balance of payments or employment, the net measure is relevant. Therefore, both gross and net measures are used in the subsequent analysis.

Nevertheless, the issue of gross versus net measures of the pattern of trade raises a fundamental theoretical issue. Both the Heckscher-Ohlin and the Ricardian theory predict that a country will export and not import a particular commodity, and yet our data show that exports and imports within the same industry are a common phenomenon. Since increasing the extent of disaggregation does not solve the problem, and since classifying a refrigerator from Italy as a different commodity belonging to a different industry as compared with a refrigerator from the U.S. would leave us with little to explain, the dilemma remains. It is possible that the new theory of demand will eventually provide some help in sorting out the theoretical issues. In the meantime, Harkness and Kyle (1973) suggest that the dependent variable should be dichotomous, and they use probit analysis in order to determine which independent variables provide a significant explanation about whether or not an industry is likely to be an export or an import industry. The categorization into export or import industries is based on the net balance 
of trade, but there is nothing sacred about this particular criterion. Thus, it is apparent that industries where exports and imports are nearly balanced may fall into one category in one year and another category in the next. Therefore, practical considerations dictate the use of a continuous dependent variable even though theoretical purity is damaged thereby.

The primary purpose of this paper will be to determine the structural characteristics of Canada-U.S. trade in manufactured products, and not to estimate the factor content of Canada's total trade. ${ }^{5}$ However, both primary and secondary manufacturing industries are included and $78 \%$ of all Canadian exports and $76 \%$ of all Canadian imports of manufactured goods involved the United States in 1964 (Wilkinson, 1968, 180) i.e., before the Auto Pact raised the percentages still further. Therefore, Baldwin's concern over the fact that the Heckscher-Ohlin theorem need not hold bilaterally in a world with many countries and more products than factors will not be taken into account explicitly in the following discussion.

\section{The Determinants of the Pattern of Trade}

The determinants of the pattern of comparative advantage considered here can be divided into four major groups: factor proportions variables, technology variables, scale variables and resistance variables.

Special emphasis will be placed on the variables which reflect the neo-factor proportions theory because of the following considerations. First, based on the Leontief paradox one would predict that Canadian exports to the U.S. would tend to be concentrated in capital intensive industries, but how is this relationship altered by introducing a variable reflecting resource intensity? Second, how are Baldwin's findings on the impact of the skill variables on Canada's net trade position affected by the use of Canadian as 
opposed to U.S. coefficients? A priorl one would argue that the skillabundant U.S. would have a competitive edge in industries using relatively large amounts of professional and technical manpower, but the possibilities of economizing on scarce resources may weaken this relationship when Canadian coefficients are employed.

Although several education levels (elementary, secondary, university) based on Canadian data have been used in addition to the proportion of an industry's workers falling into different skill classes as explanatory variables, certain alternative human capital measures have been omitted. Thus, one might argue that skill class variables ignore the contribution of formal training toward increasing the effectiveness of a worker in a particular occupation. Moreover, education levels, besides lacking refinement, take no account of on the job training. However, other measures of human capital such as capitalizing the wage differential between skilled and unskilled labour, or using direct education expenditures and foregone earnings to estimate the cost of human capital have weaknesses of their own. (Stern, 1973, 17). These considerations plus data limitations dictated the use of skill variables and education levels in the present study. The introduction of technological variables can be justified in terms of the Ricardian theory as well as the more recent technology gaps and product cycle theories. As already indicated, the consideration of these variables has the added advantage of permitting an evaluation of the relative merits of the neo-factor proportions and the neo-technology theories. By estimating production functions one could derive the rates of technical change in industries and relate these to industry exports, imports and the trade balance, (Weiser and Jay, 1972, 452) but the data requirements are voluminous; more specifically, 
capital stock data over time on a three digit industry basis are required. Moreover, this approach does not uncover the determinants of the extent and direction of technical change, and hence, the more fundamental causes of comparative advantage.

The use of research and development expenditure data also creates problems, and again accurate figures on a three digit industry basis are not available in Canada. The usual approach has been to adopt the proportion of professional and technical workers as a proxy for R\&D (Wilkinson, 1968, 143), but this variable is more relevant for the factor proportions theory. Admittedly, Branson (1971, 756) using a sample of sixty-one industries was able to show that $R \& D$ had a positive and significant impact on net exports of U.S. industries even when a human capital variable (also significant) was introduced into the equation. The same results for a restricted sample of industries were obtained when the proportion of professional and technical manpower was included, but he did not introduce both variables into the same equation--one suspects because of multicollinearity problems. Perhaps, data on scientists, engineers and technical workers in research activities would be most appropriate for testing the technology gap theory. However, the rank correlation coefficient for 30 U.S. industries between the proportion of scientists and engineers and the proportion of scientists and engineers in research activities is 0.960 while the same statistic between the former variable and the proportion of scientists, engineers and technical workers is 0.992 (National Science Foundation, 1965). A11 of these data point to the difficulty of separating the neo-factor proportions from the neo-technology theories on the basis of skill class or $R \& D$ variables. 
Fortunately, Hufbauer (1970) has developed a set of data based on U.S. sources which allows the investigator to get beyond research and development or skill class variables. He argues that the technology gap theory is intimately connected with the age of products, and thus, the most technologically advanced country (the United States) would tend to export products which have appeared relatively recently $(1970,184-89)$. The "newness" of products in an industry can be measured by examining their dates of appearance in international trade and using an appropriate weighting scheme.

Hufbauer apparent1y believes that batch production of differentiated products designed for the specific requirements of various customers as opposed to mass production of standardized products characterizes the early phase of the life cycle of a product. Therefore, he uses the variation of unit values of the same product category exported to different countries as a proxy variable for the extent of batch production or mass production in an industry. A greater variation in unit values indicates that the product category belongs to an industry where batch production predominates, and therefore, the U.S. with her abundance of R\&D imputs and external services would have a comparative advantage in this industry. Hufbauer recognizes the obvious weakness of his variable, namely, that variation in unit values may merely reflect differences in economic conditions in the importing countries in the given year. Moreover, it can be argued that he has not been successful in discriminating between the technology gap and product cycle theories with his variables. 6

There is a conceptual problem in distinguishing these theories because both emphasize the monopoly element in new products, and imply that traditional cost factors come into play once knowledge about the innovation becomes widespread. Nevertheless, the correlation coefficient between Hufbauer's proxies 
for the technology gap and product cycle theories is not significantly different from zero at the $1 \%$ level, and he may indeed be capturing some nontechnological aspects of "newness" of products with his product differentiation variable, and this is a key element of the product cycle theory (Finger, $1973,12)$. A weakness in both theories is their difficulty in handling process as opposed to product innovations unless one were to convert old products produced with new processes into "new" products, but this poses no insurmountable empirical as compared with theoretical problems (Baumann, . $1973,1009-10)$.

As already noted, one must be careful not to interpret the product cycle theory strictly in terms of the technological factor since the marketing side may be another crucial determinant of comparative advantage in "new" products. Thus, Finger (1973, 21-23) argues that U.S. comparative advantage is concentrated in industries where the rate of product turnover is high, whether or not the "new" products only involve trivial design or model change on the one hand, or involve more fundamental discoveries of the laboratory and research establishment on the other. While admitting that Finger's variable has a multidimensional content one must, however, caution against the view that Vernon emphasized the technological factor alone since the latter stresses the importance of external services including marketing know how (Vernon, 1966, 191-96).

When cconomists deal. with the issue of economies of scale, it is often not very clear what sources of economies of scale (or the lack thereof) are being considered, and whether these economies arise at the plant, firm or industry level. The lack of precision in empirical work is understandable 
since one would require comparative data on the total output over time of each product including the output profile over time, the output per unit of time, and the extent of standardization among products as well as the appropriate productivity and cost data in order to make a start in determining the causes of economies of scale whether static (e.g., indivisibilities) or quasi-dynamic (e.g., learning economies). 7

Daly, Keys and Spence (1968, 20-23) imply that static diseconomies of scale connected with the length of production runs are the main problem in certain Canadian manufacturing industries. Both the small total output of a particular product over time for a protected domestic market, and the degree of product differentiation in secondary manufacturing limit the extent of mechanization and increase downtime. Without denying the validity of this particular thesis, one must point out that some industries do not have frequent model changes, but instead are characterized either by the same product lines over time or entirely new products which would lead to different causes of diseconomies of scale although these may be just as detrimental to competitiveness. Moreover, data on the length of production runs are unavailable on a disaggregated basis. Therefore, the researcher has no choice, but to use measures of economies of scale at the plant level which do not differentiate with respect to the source of these economies.

For example, Baldwin $(1971,135-38)$ uses the proportion of industry output supplied by plants with two hundred and fifty or more employees. Little justification can be found for using this measure although the fact that similar data can be obtained for Canada makes it useful for comparison purposes. A more sophisticated measure is provided by Hufbauer (1970, 17681) who estimates an industry scale elasticity parameter " $\alpha$ " from the 
formula $v=\mathrm{kn}^{\alpha}$ where "v" represents the ratio between value added per man for a given size class of plant and the average value added per man for all establishments in an industry, " $n$ " is the number of men employed per establishment in the given size class and " $k$ " is a constant. In the actual estimation of the equation, a double $\log$ form is used.

The weakness of this approach (which is also shared by the Baldwin approach) arises from a possible systematic relationship between plant size and (i) product type (ii) quantity and quality of human and physical capital and (iii) monopoly power that causes an upward bias in estimates of " $\alpha$ ". In the light of this revelation, it is surprising that the scale economies estimates of Hufbauer tend to be lower than those derived from engineering data. However, one should recognize that most engineering estimates of economies of scale also contain an upward bias, and Hufbauer's estimate would have a downward bias if the true relationship between value added per man and size of plant is curvilinear in logs. 8

Perhaps the ideal measure of economies of scale would be an estimate of the minimum efficient scale (M.E.S.) of plants for each industry. One could then argue that a country with a large domestic market like the United States would have a comparative advantage in industries where the MES is high. Implicit in the Baldwin measure is the view that a plant of 250 employees represents the MES, but this is arbitrary and the MES can be established more rigorously through estimating cost functions, engineering data, or the survivor technique. Thus, Bhagwati $(1970,273)$ wonders why research on the pattern of trade does not make wider use of results obtained by the survivor technique. However, from a theoretical view point it is impossible to attribute the relative growth of output in a particular size class of plant to economies of scale 
alone. Moreover, empirical work is hampered by the limited sample of industries for which the survivor technique leads to unambiguous results on the question of MES. Thus, Shepherd $(1967,118-19)$ was able to derive partially clear results on the optimal size range of plants (where the lower boundary of the range would represent the MES) in only 44 of 117 industries. Moreover, since the survivor technique does not measure the degree of economies of scale, the Hufbauer measure would seem to be superior although attempts should be made to correct for possible biases in future research.

Some researchers have suggested that firm level economies of scale may be an important source of comparative advantage for large economies like the United States. These scale economies arise out of management functions which are generally centralized at the head office even in the case of multi-plant firms. One should be careful to note that the small size of the Canadian market does not necessarily lead to a scale economies problems since subsidiary plants of large U.S. firms supply the domestic market to a greater or lesser extent depending on the industry. Unfortunately, it was not possible to derive measures for the different types of firm level economies such as economies in $R \& D$, marketing, risk bearing and purchasing of inputs. Moreover, the concentration ratio in an industry which is a possible proxy for firm level economies may be high for other reasons such as the ability to earn monopoly profits. Therefore, some test of the closeness of the relationship between the concentration measure and the alleged existence of scale economies is clearly desirable. In order to do this, those industries which Pratten (1971) categorized as having economies of scale in $R \& D$, marketing and risk bearing were separated from our sample of industries. (Pratten used interviews, survey techniques and engineering data to determine where firm level economies existed). Subsequently, it was 
established that the mean value of the four firm concentration ratio was 0.276 for all industries and 0.406 for the restricted sample and the difference be:tween these means turns out to be significant. It may be concluded that industries with firm level economies tend to be more concentrated. Further evidence on this point can be derived from the fact that the simple correlation coefficient between the extent of multi-plant operations in an industry and the concentration ratio is 0.66 . One would predict that the existence of firm level economies would increase U.S. competitiveness on the assumption that the size of the domestic market has an important bearing on firm size.

In the discussion of the dependent variable, it was noted that when industry exports are scaled by world exports for that industry, better empirical results can be achieved. One reason for this is that this particular form of the dependent variable corrects for interindustry differences in resistance variables such as tariff and non-tariff barriers, transportation costs, and other information and transaction costs. When a variable such as exports in relation to output is used, proxies for these factors should be introduced explicitly into the model. Unfortunately, data on non-tariff barriers and information costs are either unavailable or not in usable form. ${ }^{9}$ On the question of tariffs, one might hypothesize that the higher the U.S. effective rate of protection on a particular industry's commodities, the lower would be Canadian exports to the U.S., and the same relationship would supply with respect to Canadian imports and the Canadian effective tariff rate. However, the fact that a country would tend to give high rates of effective protection to industries where imports are high obscures the expected relationship, and attempts at introducing tariff rates have not been noticably successful. The one exception to this last statement is Wilkinson (1968, 144-49) who found that for Canadian secondary manufacturing industries the U.S. effective 
tariff rate has a detrimental effect on exports and the Canadian nominal tariff rate has a significant negative impact on imports as a proportion of domestic production. Wilkinson (1968, 134-35) also argues that the Canadian tariff would have a negative effect on exports because entrepreneurs would not undergo the necessary rationalization to make them cost competitive, and that foreign tariffs would have a positive effect on Canadian imports for a similar reason. Again the empirical results confirm his a priori expectations, but only for the secondary manufacturing industries.

A valuable set of data on shipping cost of a dollar of product value by industry has recently become available, and even though it is based on U.S. sources alone, it would appear to be the best method of introducing the effects of distance into the model. (Murphy, 1972). One would expect that both exports and imports would be inversely related to transportation cost per dollar of product value although shipping charges are not independent of product value. Moreover, in Canada--U.S. trade, distances between the two countries are often far less than distances between regions of the same country. Therefore the influence of transportation costs on Canada--U.S. trade cannot be neatly summarized by some transportation cost variable.

Most of the literature on foreign trade considers product movements and factor movements as substitutes, and hence, one can hypothesize that sales in the Canadian market by U.S. subsidiaries would be inversely related to Canadian imports for any given industry. Thus, U.S. firms could exploit their competitive edge, no matter what the source, either through export sales or sales by their subsidiaries with the choice being decided on the basis of the height of tariff barriers and relative costs 
of production (Horst, 1972, 37-45; Baumann, 1973, 1009-12). Recent1y, Schmitz and Helmberger $(1970,761-67)$ have argued that product trade and capital flows in the form of foreign direct investment are complements and not substitutes although their argument would appear to be applicable mainly where capital is exported because natural resources can be imported. More specifically, if country $I$ is capital abundant and has a large demand for a natural resource product which can only be produced efficiently in capital scarce country II, then foreign direct investment by country I will lead to increased trade between the two countries. If one accepts the Schmitz and Helmberger argument, then the export to output ratio for Canadian industry's would be positively related with the extent of subsidiary production. However, their argument only applies to the primary sector (excluded here) or possibly the primary manufacturing sector. The argument for a complementary relationship between trade and foreign direct investment in secondary manufacturing would appear to depend on the extent of reduction in information costs $i_{.} e_{\text {. }}$, resistance or the degree of international integration of production within the multinational enterprises of a particular industry. Wilkinson $(1968,139-40)$ suggests that subsidiaries may serve as sales agencies in which case the import to output ratio would vary positively with the extent of foreign ownership. 


\section{Empirical Results}

The results of the estimation by ordinary least squares of various versions of the multiple regression model are presented in Tables I-IV. From Table I, it is apparent that Canada's imports from the U.S. tend to be concentrated in industries with a low capital labour ratio $(K / L)$ as the Leontief Paradox 1iterature suggests. Moreover, Canada's imports originate from industries which make little use of crude materials (CRU), but this variable is only significant when the capital intensity variable is dropped (cf. equations $1(a)$ and $1(c)$ ). As expected, the two variables are correlated with the simple correlation coefficient being 0.39 , and this leads to multicollinearity problems.

A11 of the equations indicate that Canada's imports from the U.S. are derived from industries employing relatively large numbers of professional and technical (PROT) workers. The relationship between imports and the proportion of managers, (MAN), as well as foremen, craftsmen and operatives (CRAF) is also positive, but not significant. The opposite sign applies in the case of the proportion of clerical, sales (CLER) and unskilled (LAB) workers. ${ }^{10}$ The final determinant of Canada's imports from the U.S. is the existence of economies of scale at both the plant (SCA) and firm (CONC) level, but since these variables are collinear (the correlation coefficient is 0.24 ) they only enter significantly when separately introduced (cf. equation $1(d)$ ).

While the results for imports from the U.S. are fairly encouraging, the same cannot be said for the export equation. One would have expected that Canadian exports would be concentrated in crude material intensive industries, but although the sign is correct, this variable is not significant. 


\section{Table I - Empirical Results}

NEO-FACTOR PROPORTIONS (SKILL VERSION)

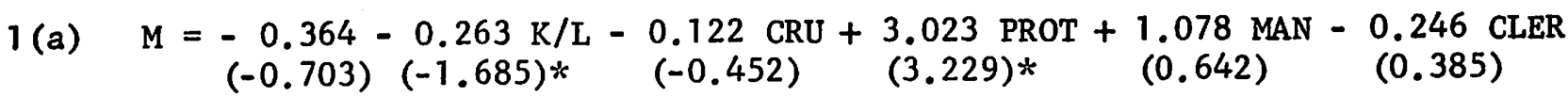

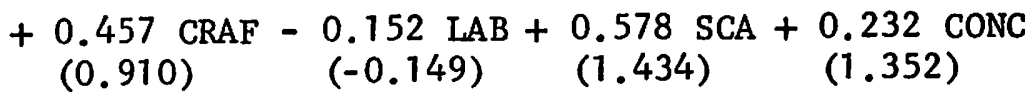

$$
\begin{aligned}
& \overline{\mathrm{R}}^{2}=0.215 \quad \mathrm{~F}=3.257
\end{aligned}
$$

$$
\begin{aligned}
& 1 \text { (b) } M=\frac{-0.061}{(-0.767)}-\underset{(-2.370) *}{0.329 \mathrm{~K} / \mathrm{L}}+\underset{(3.738) *}{2.674 \mathrm{PROT}}+\underset{(0.940)}{0.353 \mathrm{SCA}}+\underset{(1.370)}{0.225 \mathrm{CONC}} \\
& \overline{\mathrm{R}}^{2}=0.212 \quad \mathrm{~F}=5.446 \\
& \overline{\mathrm{R}}^{2}=0.185 \quad \mathrm{~F}=4.735
\end{aligned}
$$

1 (d) $\quad \mathrm{M}=-0.354-0.354 \mathrm{~K} / \mathrm{L}+2.745 \mathrm{PROT}+0.267 \mathrm{CONC}$

$$
\begin{array}{lll}
(-0.779) & (-2.601) *(3.862) * & (1.684) * \\
\bar{R}^{2}=0.193 & F=6.273
\end{array}
$$

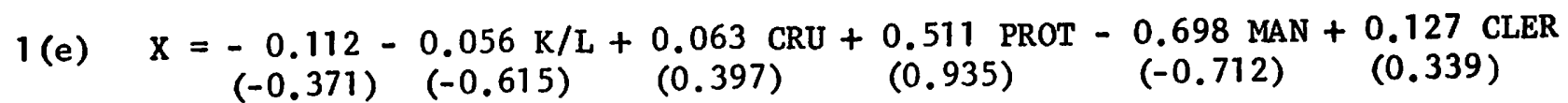

$+0.194 \mathrm{CRAF}+0.645 \mathrm{LAB}-0.108 \mathrm{SCA}+0.136 \mathrm{CONC}$

$$
\begin{array}{lll}
(0.661) \quad(1.085) \quad(-0.462) \quad(1.360)
\end{array}
$$

$$
\overline{\mathrm{R}}^{2}=-.027 \quad \mathrm{~F}=0.807
$$

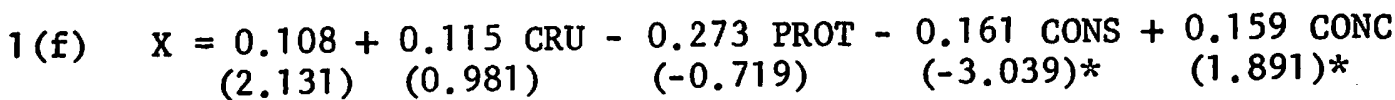

$$
\overrightarrow{\mathrm{R}}^{2}=0.120 \quad \mathrm{~F}=3.242
$$


Table I - Empirical Results (cont'd.)
1 (g) $\quad X-M=0.020+0.176 \mathrm{~K} / 0+0.390 \mathrm{CRU}-2.243 \mathrm{PROT}-0.570 \mathrm{SCA}-0.048 \mathrm{CONC}$ $(1.618) \quad(1.825) * \quad(-3.288) * \quad(-1.570) \quad(-0.299)$$$
\overline{\mathrm{R}}^{2}=0.211 \quad \mathrm{~F}=4.535
$$
1 (h) $\quad \mathrm{X}-\mathrm{M}=0.035+0.454 \mathrm{CRU}-2.000 \mathrm{PROT}-0.601 \mathrm{SCA}$

$$
\begin{array}{lll}
(2.163) * & (-3.079) * & (-1.697) * \\
\bar{R}^{2}=0.204 & F=6.632
\end{array}
$$

Notes: (a) For definition of variables and sources of data see the statistical appendix.

(b) Number of observations $=67$

(c) * denotes significant t-value at the $95 \%$ level. 
The possible explanations for this result are: i) Canada does not have an abundance of all raw materials, and therefore, the CRU variable must be refined to reflect this fact, and ii) trade barriers between Canada and the United States in crude material intensive products such as foodstuffs prevent the forces of comparative advantage from operating. However, strong evidence exists in equation 1 (f) that Canada's exports are largely producer goods, or are not consumer goods as the significant, negative coefficient on the coNs variable indicates. 11

One surprising result involves the apparent positive effect of firm level economies (CONC) on both imports and exports which implies that these economies are a trade creating factor.

From the last two equations of Table I, one can conclude that a favorable net balance of trade for Canadian industries is connected with capital and raw material intensive processes as opposed to skill or human capital intensive processes. Moreover, Canada appears to have a definite disadvantage in industries where scale economies are important.

The results from the education version of the neo-factor proportions model in Table II are similar to those of the skill version. However, the adjusted $\mathrm{R}^{2}$ is somewhat reduced and the scale variables lose their significance. Moreover, the high education variable (EDH) has the wrong sign. Errors of measurement in this variable are the most 1ikely explanation for the anomaly. One would expect a high correlation between the proportion of professional and technical workers in an industry and the proportion of employees with at least some university 


\section{Table II - Empirical Results}

Neo-Factor Proportions (Education Version)

2(a) $\quad \mathrm{M}=\underset{(-0.904)}{0.143} \mathrm{~K} / \mathrm{L}-\underset{(-0.635)}{0.159} \mathrm{CRU}-\underset{(-2.258)}{0.515}$ * EDL $+\underset{(2.802) *}{0.910}$ EDM $-\underset{(-0.131)}{0.200}$ EDH

$$
\overline{\mathrm{R}}^{2}=0.166 \quad \mathrm{~F}=4.296
$$

2(b) $\quad M=-0.225 \mathrm{~K} / \mathrm{L}-0.471 \mathrm{EDL}+0.741(\mathrm{EDM}+\mathrm{EDH})$

$$
(-1.742) * \quad(-2.816) * \quad(5.137) *
$$

$$
\overline{\mathrm{R}}^{2}=0.183 \quad \mathrm{~F}=11.243
$$

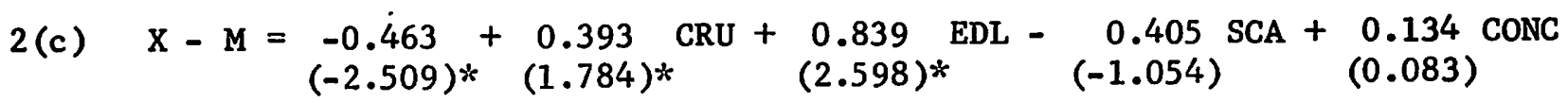

$$
\overline{\mathrm{R}}^{2}=0.165 \quad \mathrm{~F}=4.270
$$

2(d) $\mathrm{X}-\mathrm{M}=\underset{(0.700)}{0.060}+\underset{(1.863) *}{0.272} \mathrm{~K} / \mathrm{L}+\underset{(0.480)}{0.050} \mathrm{CONS}-\underset{(2.343) *}{2.421} \mathrm{EDH}-\underset{(-1.345)}{0.550 \mathrm{SCA}}$

$$
\mathrm{R}^{2}=.095 \quad \mathrm{~F}=2.735
$$

NOTES: See Table I 
education (EDH), and the former variable did, of course, give the hypothesized result. The level of formal education in Canadian industries in 1961 was relatively low, and one suspects that on the job training may have been used in order to fill gaps in professional and technical manpower in skill intensive industries. Only new data from the 1971 Census can shed any light on this problem, but when the proportion of workers with secondary and university education is added together, (equation $2(\mathrm{~b})$ ) then the predicted result holds. This is also the case when the net balance of trade is the dependent variable. Note that the constant term has been suppressed in some formulations because the education variables sum to unity.

In Table III, variables reflecting the neo-technology theories of trade have been introduced into the analysis. In general, these formulations of the model provide a better fit as judged by the adjusted $\mathrm{R}^{2}$ than the factor proportions versions. Moreover, the robustness of the relationship between the scale variables and the patterns of trade is improved.

The import to output ratio tends to be high in those industries which produce new products as shown by the first trade date variable (FTD) which reflects the technology gap theory. Moreover, Canada tends to import more in industries with highly differentiated product lines, i.e., products with technologically unique characteristics or features. Thus, the PROD variable is always significant and positive which experiments with an advertising variable which reflects another dimension of product differentiation were unsuccessful. More specifically, advertising intensity may be aimed at creating an impression of uniqueness where non exists 


\section{Table III - Empirical Results}

NEO-TECHNOLOGY VERSION

3(a) $\mathrm{M}=-0.884+0.014 \mathrm{FTD}+0.308 \mathrm{PROD}+0.794 \mathrm{SCA}+0.362 \mathrm{CONC}$ $(-3.882) *(2.839) *(3.124) * \quad(2.277) * \quad(2.491) *$

$$
\overline{\mathrm{R}}^{2}=0.314 \quad \mathrm{~F}=8.568
$$

3 (b) $\quad \mathrm{M}=-\underset{(-3.712) *(2.689) *}{0.856}+0.013 \mathrm{FTD}+\underset{(3.188) *}{0.316 \mathrm{PROD}}+\underset{(2.571) *}{0.835 \mathrm{SCA}}+\underset{(2.571) *}{0.378 \mathrm{CONC}}-\underset{(-0.831)}{0.002} \mathrm{RPT}$

$$
\bar{R}^{2}=0.312 \quad F=6.982
$$

3(c) $\quad \mathrm{M}=-0.816+0.012 \mathrm{FTD}+0.276 \mathrm{PROD}+0.698 \mathrm{SCA}+0.302 \mathrm{CONC}+0.150 \mathrm{P}$

$$
(-3.479) *(2.420) *(2.709) *(1.956) *(1.972) * \quad(1.152)
$$

$$
\bar{R}^{2}=0.318 \quad F=7.165
$$

3 (d) $\quad M=-0.316+0.014 \mathrm{FTD}+0.314 \mathrm{PROD}+0.796 \mathrm{SCA}+0.272 \mathrm{CONC}-0.426$ ETC $(-0.918)(2.831) *(3.301) * \quad(2.371) * \quad(1.859) * \quad(-2.556) *$

$+0.018 \mathrm{ETU}$ $(0.120)$

$$
\bar{R}^{2}=0.364 \quad F=7.301
$$

$$
\begin{aligned}
& 3(\mathrm{e}) \quad \mathrm{X}=-0.005+0.003 \text { FTD }-0.147 \text { CONS }-0.067 \text { PROD }-0.013 \text { SCA }+0.157 \text { CONC } \\
& (-0.030) \quad(1.161) \quad(-2.419) *(-1.094) \quad(-0.062) \quad(1.189) \\
& \begin{array}{ll}
\overline{\mathrm{R}}^{2}=0.101 & \mathrm{~F}=2.268
\end{array} \\
& (2.412) *(-3.082) * \quad(1.892) * \quad(-1.308) \\
& \bar{R}^{2}=0.136 \quad F=4.455
\end{aligned}
$$

$3(\mathrm{~g}) \quad \mathrm{X}=0.102-0.143 \mathrm{CONS}+0.159 \mathrm{CONC}-0.00098 \mathrm{RPT}$

$$
(-2.126) *(-2.799) * \quad(1.934) * \quad(-0.634)
$$

$$
\bar{R}^{2}=0.118 \quad F=3.941
$$


Table III - Empirical Results (cont'd.)

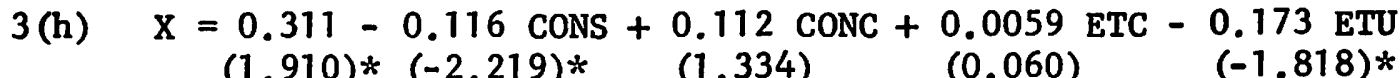

$$
\bar{R}^{2}=0.145 \quad F=3.803
$$

3(i) $\quad \mathrm{X}=0.101-0.144$ CONS +0.115 CONC $-0.005 \mathrm{P}$

$$
(1.919) *(-2.767) *(1.791) * \quad(-0.0757)
$$

$$
\bar{R}^{2}=0.112 \quad F=3.764
$$

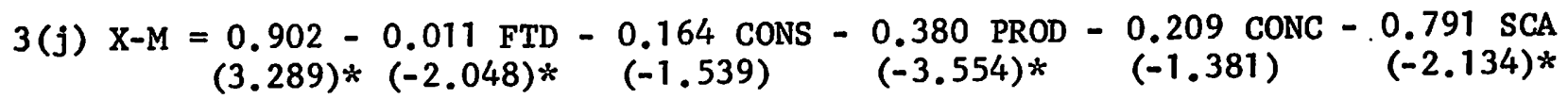

$$
\overline{\mathrm{R}}^{2}=0.249 \quad \mathrm{~F}=5.379
$$

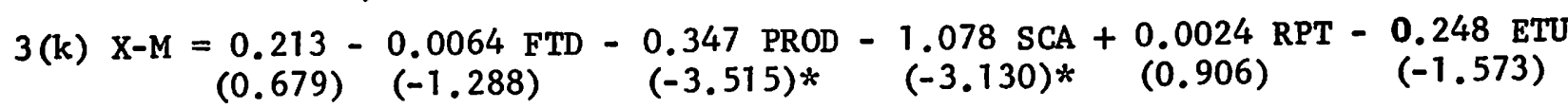

- 0.482 ETC $(2.823) *$

$$
\overline{\mathrm{R}}^{2}=0.294^{\circ} \quad \mathrm{F}=5.576
$$

Notes: See Table I. 
and this aspect will be a feature of the standardized phase and not the early phase of the product cycle. Moreover, from equation $3(f)$ it is apparent that the rate of product turnover (RPT) which includes new product development as well as style, design or model changes does not have a significant impact on the import/output ratio of Canadian industries, nor does it have the hypothesized sign (cf. equation $3(\mathrm{~g})$ ). Therefore, it can be concluded that technological innovation as well as scale are the dominant factors in determining the Canada-U.S. patterns of trade. However, it should be noted that the export/output ratio of Canadian industries is also positively related to the technology gap variable and the firm level economies of scale variable (cf. equation $3(e)$ ). Therefore, there is some evidence that these variables have a trade creating effect although in terms of the net balance of trade Canada appears to be weak in industries with these structural characteristics. The effective tariff has the expected result, i.e., the Canadian effective tariff (ETC) is inversely related to the import/output ratio which the U.S. effective tariff (ETU) is inversely related to the export/ output ratio (cf. equations $3(d)$ and $3(h)$ ). Moreover, the net balance of trade is inversely related to the Canadian tariff presumably because effective protection would be high where policymakers could hope to influence this ratio. The U.S. effective tariff rate does not have a significant, positive effect on the import/output ratio, and hence, there is no support for the hypothesis that the U.S. tariff per se prevents operations on a sufficient scale for Canadian plants to be competitive. This contradicts the result of Wilkins on $(1968,149)$ for Canadian secondary manufacturing industries, but he did not have scale variables in his model, and factors other than tariffs such as transportation costs, non-tariff barriers to 
trade and the goals of firms affect the scale of operations.

The extent of subsidiary production has no clear cut impact on the pattern of trade. The import/output ratio is directly related to subsidiary production (P) and the export/output ratio is inversely related to the same variable, but neither variable is significant. This probably results from the contradictory forces which have been discussed earlier on.

Up to this point, the entire discussion has been in terms of Canadian data as far as the neo-factor proportions versions are concerned. This might lead to the conclusion that the neo-technology approach only leads to improved results because of the use of U.S. data for the independent variables. Therefore, in Table IV, the results for the neo-factor proportions version with Baldwin's U.S. data are presented. Unfortunately, it was impossible to use the same sample of industries because of data limitations, and therefore, no definitive statement on the impact of one country's coefficients as opposed to another can be drawn. Nevertheless, it is apparent that the same variables turn out to be significant, i.e., a favorable net balance of trade for Canada is associated with capital and perhaps crude material intensive industries while the existence of plant level economies of scale, a high education level and the intensive use of engineers and scientists (ES) is associated with an unfavorable balance of trade for industries. These results may be compared with those of Tables I and II as well as equation 4 (d) of Table IV which refers to this new sample of industries. Note that the adjusted $R^{2}$ is higher for the sample of industries in Table IV whether Canadian or U.S. coefficients are employed. ${ }^{12}$ It should also be mentioned 


\section{Table IV - Empirical Results}

NEO-FACTOR PROPORTIONS (EDUCATION VERSION)

\section{U.S. Coefficients}

$$
\begin{aligned}
& 4 \text { (a) } \quad \mathrm{X}-\mathrm{M}=0.344+0.530 \mathrm{CRU}-2.738 \mathrm{EDH}-2.229 \mathrm{SCA}+0.029 \mathrm{CONC} \\
& (1.893) *(1.145) \quad(-2.214) *(-3.014) *(0.302 \\
& \bar{R}^{2}=0.369 \quad F=10.633 \\
& \text { 4(b) } \quad \mathrm{X}-\mathrm{M}=0.251+1.908 \mathrm{~K} / \mathrm{L}-3.683 \mathrm{EDH}-1.928 \mathrm{SCA}+0.022 \mathrm{CONC} \\
& (1.376) \quad(2.031) * \quad(-2.873) * \quad(-2.645) *(0.235) \\
& \overline{\mathrm{R}}^{2}=0.421 \quad \mathrm{~F}=12.989 \\
& 4 \text { (c) } \quad \mathrm{X}-\mathrm{M}=0.044+1.378 \mathrm{~K} / \mathrm{L}-9.883 \mathrm{ES}-1.512 \mathrm{SCA}+0.028 \mathrm{CONC} \\
& (0.326)(1.663) \quad(-3.628) *(-2.111) *(0.318) \\
& \bar{R}^{2}=0.487 \quad F=16.663
\end{aligned}
$$

\section{Canadian Coefficients}

$$
\begin{aligned}
& 4 \text { (d) } \quad \mathrm{X}-\mathrm{M}=-0.038+0.557 \mathrm{CRU}-0.0013 \mathrm{EDH}-2.817 \mathrm{SCA}+0.037 \mathrm{CONC} \\
& (-0.449) \quad(1.607) \quad(2.339) * \quad(-4.078) *(0.063) \\
& \overline{\mathrm{R}}^{2}=0.442 \quad \mathrm{~F}=14.074
\end{aligned}
$$

Notes: (a) See Table I.

(b) Number of Observations $=35$. 
that Baldwin's data measure both direct and indirect requirements of capital, crude materials, etc. but experimentation with total and only direct coefficients where the data were available did not suggest that this difference affected the results. ${ }^{13}$

How does the empirical work summarized in the above tables compare with that of other researchers? In terms of explanatory power, Wilkinson's results (1968, 143-51) were at least as good for secondary manufacturing exports and primary manufacturing imports, but his adjusted $\mathrm{R}^{2}$ fell to zero in the case of primary manufacturing exports and was relatively low for secondary manufacturing imports. The division into primary and secondary manufacturing industries was based on whether or not $50 \%$ of the material inputs of an industry arose from the primary sector (agriculture, forestry, mining, etc.) of the Canadian economy, and since a crude materials coefficient was introduced explicitly in the present model, this division seemed inappropriate. Comparison with Wilkinson's results is also made difficult because his dependent variables refer to total and not Canada-U.S. trade. Of course, Wilkinson did not deal with the influence of technological and scale factors except insofar as he introduced the proportion of professional and technical workers into his model, and saw this variable as a proxy for R\&D. His results with this variable were similar to those discussed above, except that he found a significant and positive association between Canadian secondary manufacturing exports and this variable. In addition, to the trade creating effect discussed earlier this result may reflect a comparative advantage in skill intensive industries relative to countries other than the United States (but see p. 23 below). 
The only other relevant empirical work on the Canadian situation is found in Baldwin $(1971,137)$ who discovered that a favourable net balance for Canadian industries is related to capital and unskilled labour intensive production. However, the explanatory power of his equation is rather low, and we cannot reject the hypothesis that all his coefficients are equal to zero. Nevertheless, Baldwin's results for total U.S. trade and areas other than Canada, as well as Branson's $(1971,756)$ findings do reveal considerable empirical support for the neo-factor proportions approach. Why does this theory do poorly relative to the neotechnology theories in the present study? An obvious explanation is that Hufbauer's data have only recently become available, and hence, few comparative studies have been made. There is some validity to this statement, but even Finger $(1973,5)$ who relies on Hufbauer's data as well as his own RPT measure concludes that: "The results of this ana1ysis reconfirm the influence of human and physical capital intensity as determinants of the level of U.S. exports and imports, and show also a significant role for the product cycle theory." Branson would not grant the neo-technology theory even this much since his empirical work has convinced him of the "validity of a basic three factor view of trade in manufactured goods as opposed to a more complicated model with additional technological variabes" (1971, 757).

Even though one might argue that Branson's empirical results only provide support for Finger's more cautious statement, the evidence does suggest that the Canadian situation represents a special case. For example, the introduction of physical capital and skill variables does not lead to technology variable becoming insignificant in the estimation of the models presented in Table III although this tendency has been observed in 
studies on the U.S. pattern of trade (Branson, 1971, 757). Moreover, Weiser and Jay $(1972,462)$ have shown that Canada's exports are the least technological change intensive in a sample of eleven industrialized countries while U.S. exports are the second most technological change intensive. The Gray Report (1972, 119) ranks Canada last among industrialized countries in terms of performance in technological innovation. Therefore, it is not surprising that technological variables are the most important explanatory factors of the Canada-U.S. pattern of trade.

\section{E. Conclusion}

The main conclusions of this study can be summarized in the following manner:

1. A multi-dimensional explanation of the pattern of Canada-U.S. trade is required at least as far as Canadian imports of manufactured goods and the net balance of trade are concerned.

2. Canada's exports to the U.S. are concentrated in producer goods industries and industries where firm level scale economies are important. However, the explanatory power of all models with the export/output ratio as the dependent variable is weak.

3. The neo-technology theories provide a better explanation of the Canada-U.S. pattern of trade than the neo-factor proportions theory although physical capital, natural resources and professional and technical skills do affect the patterns of trade between the two countries.

4. The use of U.S. coefficients as opposed to Canadian coefficients does not appear to make any major difference as far as the empinical results are concerned. 
The paper leads to certain suggestions for further research. First, several improvements in the explanatory variables are desirable and will soon become feasible. Thus, capital stock data on the threedigit industry level is currently being developed for Canada, and the results of the 1971 Census will be useful in bringing the skill and education variables up to date. Moreover, the crude materials variable can be refined by taking into consideration that Canada does not have an abundance of all raw materials and substitutability may be quite low. In a previous section, certain weaknesses of the technological and scale variables have already been mentioned. Given that the former type of variable plays an important role in the pattern of trade, one would like to see more research on the determinants of the diffusion of new products and processes.

Second, and this point is crucial for policy purposes, additional research on the determinants of changes in the pattern of trade is desirable. The present study refers to a specific point in time, and, therefore, affords only "limited insight into the initial determination of comparative advantage and the process of change through time" (Stern 1973,6). For example, is it the case that the liberalization of trade during the 1960 's has led to an improvement in Canada's comparative advantage in industries where economies of scale are important? This question can be answered by obtaining the relevant data for the dependent variable and using modification of the above models. From a theoretical viewpoint, this approach also affords an opportunity of testing the essentially dynamic content of the neo-technology theories. 


\section{Footnotes}

* The author would like to thank his research assistants Nguyen $\mathrm{H}$. Manh and Ellen Hall for their help with the tedious data work. Robert Baldwin kindly made available to me his data on U.S. coefficients.

${ }^{1}$ For surveys of this work consult (Johnson, 1968) and (Stern, 1973).

2 It is only an attempt because some proxy variables can be interpreted as representing either the neo-factor proportions or neo-technology theories. Moreover, multicollinearity problems arise in the regression analysis although recently Leamer (1972) has suggested the use of Bayesian methods to deal with this difficulty.

3 As every international trade economist knows, the conversion of data from the SITC scheme to the U.S. and Canadian SIC poses a considerable challenge. Details on the actual approach taken can be obtained from the author.

${ }^{4}$ See discussion below, pp. 13-14.

${ }^{5}$ Actual factor requirements (both direct and indirect) of the commodity bundle of Canadian exports and imports could be worked out with input-output data.

${ }^{6}$ Consult the commentary by Kindleberger $(1970,280-86)$ and Kravis (1970, 186-95).

${ }^{7}$ Aubrey Silberston $(1972,369-91)$ provides a complete taxonomy of the various dimensions of economies of scale.

${ }^{8}$ This possibly provides an answer to a situation which Hufbauer $(1970$, 180-81) calls puzzling.

${ }^{9}$ The only exception to this statement is the work by Baldwin (1970, 154-65) who provides some estimates of nontariff distortions.

${ }^{10}$ The skill variables, other than PROT, were subsequently dropped from the regressions because they did not add significantly to the explanatory power of the equations at the $5 \%$ level. An $\mathrm{F}$ test was used to derive this result.

${ }^{11}$ A similar result was obtained by Wilkinson $(1968,146)$ for total Canadian secondary manufacturing exports. 
${ }^{12}$ This sample of industries is based on the U.S. input-output classification rather than the Canadian three digit SIC. Thus, the food and beverages sector has been aggregated into one industry. And this may have improved the results because trade barriers exist in foodstuffs between the two countries. Moreover, all of the results can be improved slightly by dropping the automobile industry as one would expect.

${ }^{13}$ It is clear that when a country's position with respect to the balance of factor services exported and imported is of primary concern, then both direct and indirect (total) coefficients should be used. The difference between the two measures would appear to depend on the extent to which intermediate products are imported. 


\section{$\underline{\text { References }}$}

Baldwin, R. E., "Determinants of the Commodity Structure of U.S. Trade," American Economic Review, LXI (March, 1971), 126-46.

, "Detcrminants of the Commodity Structure of U.S. Trade: Reply," American Economic Review, LXII (June, 1972), 465.

1970. , "Nontariff Distortions of International Trade, (Washington,

Baumann, H. G., "The Industrial Composition of U.S. Exports and Subsidiary Sales to the Canadian Market: Note," American Economic Review, LXIII (December, 1973), 1009-12. , "The Rationalizing of Canadian Industry: A Comment," forthcoming Canadian Journal of Economics.

Bhagwati, Jagdish, "Comment" on Hufbauer, and Gruber and Vernon, The Technology Factor in International Trade, (New York, 1970), 272-74.

Branson, W. H., "U.S. Comparative Advantage: Some Further Results," Brookings Papers on Economic Activity, 3: 1971, 754-59.

Daly, D. J., B. A. Keys and E. J. Spence, Scale and Specialization in Canadian Manufacturing, (Ottawa, 1968).

Finger, J. Mo, "Product Development, "The Product Cycle Theory, and United States Trade in the 1960's," unpublished paper, 1973.

Harkness, Jon and J. Kyle, "Factors Influencing United States Comparative Advantage," Paper read at the New York meetings of the American Economic Association, 1973.

Horst, Thomas, "The Iudustrial Composition of U.S. Exports and Subsidiary Sales to the Canadian Market," American Economic Review, LXII (March, 1972), 37-45.

Hufbauer, G. C., "The Impact of National Characteristics and Technology on the Commodity Composition of Trade in Manufactured Goods," The Technology Factor in International Trade, (New York, 1970), 145-231.

Johnson, H. G., Comparative Cost and Commercial Policy Theory for a Developing World Economy, (Stockholm, 1968).

Keesing, D. B., "Different Countries' Labor Skill Coefficients and the Skill Intensity of International Trade Flows," Journal of International Economics, 1, (November, 1971), 453-60.

Kindleberger, C. P., "Comment" on Hufbauer, and Gruber and Vernon, The Technology Factor in International Trade, (New York, 1970), 280-86. 
Kravis, I. B., "Comment" on Hufbauer, and Gruber and Vernon, The Technology Factor in International Trade, (New York, 1970), 286-95.

Leamer, E. E., "The Commodity Composition of International Trade in Manufactures: An Empirical Analysis," unpublished paper, 1972.

Melvin, J. R., and B. W. Wilkinson, Effective Protection in the Canadian Economy, (Ottawa, 1968).

Murphy, R., "The Determinants of the Extent of Multiplant Operations in United States Manufacturing Industries, unpublished Ph.D Dissertation, Ann Arbor, 1972.

Posner, M. V., "International Trade and Technical Change," Oxford Economic Papers, XXI (October, 1961), 323-41.

Pratten, C. F., Economics of Scale in Manufacturing Industry, (Cambridge, 1971).

Schwitz, A. and P. Helmberger, "Factor Mobility and International Trade: The Case of Complementarity," Ámerican Economic Review, IX (September, 1970), 761-67.

Shepherd, W. G., "What Does the Survivor Technique Show About Economies of Scale," Southern Economic Journal, 34 (July, 1967), 113-122.

Silberston, A., "Economies of Scale in Theory and Practice," Economic Journal, 82 (March 1972, Supplement).

Stern, R. M., "Testing Trade Theories," University of Michigan Seminar Discussion Paper, 1973.

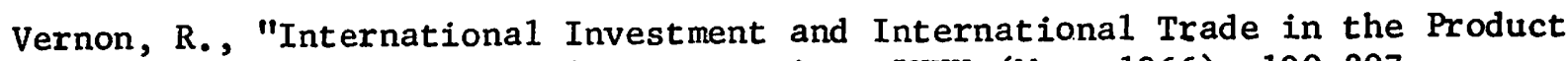
Cycle," Quarterly Journal of Economics, LXXX (May, 1966), 190-207.

Weiser, L., and K. Jay, "Determinants of the Commodity Structure of U.S. Trade: Comment," American Economic Review, LXII (June, 1972), 459-64.

Wilkinson, B. W., Canada's International Trade: An Analysis of Recent Trends and Patterns, (Montreal, 1968). 


\section{Statistical Appendix}

Data Sources: I am indebted to Baldwin and Hufbauer for the U.S. version of the independent variables. The interested reader should consult these articles for precise definitions and sources.

$x_{i} \equiv$ The ratio of Canadian exports to the U.S. over total Canadian shipments in industry $i$. An average of 1969 and 1970 data was used to minimize the problem of short term fluctuations. Sources: Trade Relations Council of the United States, Employment, Output, and Foreign Trade of U.S. Manufacturing Industries 1969/70, (Washington, 1972) ; Statistics Canada, General Review of the Manufacturing Industries of Canada, (Ottawa: Information Canada, various issues).

$M_{i} \equiv$ The ratio of Canadian imports from the U.S. over total Canadian shipments. Source: Same as $\mathrm{X}_{i}$.

$\mathrm{K}_{i} / \mathrm{L}_{i} \equiv$ The dollar value of net fixed assets per man for 1969 in industry $i \times 10^{-5}$. Sources: Statistics Canada, Corporation Financial Statistics, (Ottawa: Information Canada, 1972), and Review of Manufacturing Industries of Canada, 1969 (Ottawa: Information Canada, 1972).

$\mathrm{K}_{i} / 0_{i} \equiv$ The dollar value of net fixed assets per million dollars of shipments for industry $i$ in 1969. Source: Same as $k_{i} / L_{i}$.

$\mathrm{CRU}_{i} \equiv$ Direct requirements of crude materials per dollar value of gross output for 1967 in industry $i$. Source: Statistics Canada, The Input-Output Structure of the Canadian Economy, 1961 (Ottawa: Information Canada, 1969). Crude materials are defined to include all shipments arising from the primary sector of the Canadian economy.

PROT $_{i} \equiv$ The proportion of professional and technical workers for 1961 in industry i. Source: Statistics Canada, Census of Canada, 1961, Vo1. 3, Part 3 (Ottawa: Information Canada, n.d.).

MAN $_{i} \equiv$ The proportion of managerial workers for 1961 in industry $i$. Source: Same as $\mathrm{PROT}_{i}$.

CLER $_{i} \equiv$ The proportion of clerical and sales personnel for 1961 in industry $i$. Source: Same as PROT $_{i}$.

$\mathrm{CRAF}_{i} \equiv$ The proportion of craftsmen and operatives for 1961 in industry $i$. Source: Same as $\mathrm{PROT}_{i}$.

$\mathrm{LAB}_{i} \equiv$ The proportion of labourers for 1961 in industry $i$. Source: Same as $\mathrm{PROT}_{i}$.

$E_{i} \equiv$ The proportion of the labour force with 0-8 years of education for 1961 in industry $i$. Source: Statistics Canada, Unpublished Census Data. 


\begin{abstract}
$E D M_{i} \equiv$ The proportion of the labour force with secondary (9-12 or 9-13 years depending on the province) education for 1961 in industry $i$. Source: Same as $\mathrm{EDL}_{\mathbf{i}}$.

$\mathrm{EDH}_{i} \equiv$ The proportion of the labour force with at least some university (12+ or $13+$ years depending on the province) education for 1961 in industry $i$.

$\mathrm{SCAC}_{i} \equiv$ The ratio of shipments from plants employing more than 200 workers to total shipments for industry i. Source: Statistics Canada.

CONC $_{i} \equiv$ The four firm concentration ratio based on shipments for industry $i$. Source: Statistics Canada, Industrial Organization and Concentration in the Manufacturing, Mining and Logging Industries, 1968 (Ottawa: Information Canada, 1973).

$\mathrm{ADV}_{i} \equiv$ Advertising expenditures as a proportion of sales for 1961 industry i. Source: Statistics Canada, Market Research Handbook (Ottawa: Information Canada, 1966).

$P_{i} \equiv$ The ratio of U.S. subsidiary sales in Canada to total Canadian shipments in 1968 for industry $i$. Source: Statistics Canada: unpublished data.

$\mathrm{RPT}_{\mathbf{i}} \equiv$ The ratio of new seven digit numbers appearing over some period of time (1966-71) within a three digit commodity group in the U.S. trade classification scheme (Schedule B) to the total number of seven digit commodity numbers. Source: Finger (1973, Appendix).

ETC $_{i} \equiv$ The Canadian effective rate of protection, 1963. Source: Melvin and Wilkins on (1968, Table 1).

ETU $_{i} \equiv$ The U.S. effective rate of protection 1964. Source: Baldwin (1970, 163-64).
\end{abstract}

The following variables are based on U.S. data alone, and were obtained from Appendix Table A-2 of the Hufbauer article except for the transportation variable.

$\mathrm{SCAH}_{i} \equiv$ An estimate of " $\alpha$ " or the scale elasticity parameter in the equation $\mathbf{v}=\mathbf{k n}^{\alpha}$ where " $\mathrm{v}$ " represents the ratio between value added per man for a given size class of plant and the average value added per man for all establishments in the industry; " $n$ " represents the average number of men employed per establishment in the given size class; " $\mathrm{k}$ " is a constant. The measure is based on 1963 U.S. Census of Manufactures Data.

FTD $_{1} \equiv$ The average first trade date for the commodities produced by industry $i$. This variable was obtained by examining the detailed (1958) schedule of exportable goods of the U.S. for the first appearance of specific commodities. 
CONS $_{i} \equiv$ The ratio of consumer goods to producer goods produced by industry i. Consumer goods are defined as products which are sold to households or government acting as a consumer. The data are derived from the 1958 U.S. imput-output table and both the proportion of products sold by an industry directly to final consumers and indirectly through another industry are taken into account up to the second round. Thus, producer goods are commodities which do not reach the consumer very quickly。

$\operatorname{PROD}_{i} \equiv$ This variable is derived from the formula $U_{n} / V_{n}$ where $U_{n}$ denotes the standard deviation of U.S. export unit values for shipments of product " $n$ " (produced by industry $i$ ) to different countries and $\mathrm{V}_{\mathrm{n}}$ is the average unit value. It is a proxy for product differentiation based on 1965 export data of the U.S.

$\operatorname{TRAN}_{i} \equiv$ The shipping cost of a dollar of product value in the 1960's over a specified distance (Chicago-Cleveland in this case). It is derived from the formula $[(1) / \$ 1 / W](R)$ where $R=$ freight per pound over a specified distance and $W=$ shipping weight of $\$ 1$ of product in question. Source: R. Murphy, The Determinants of the Extent of Multiplant Operations in United States Manufacturing Industries, University of Michigan, Unpublished Ph.D. Dissertation, 1972. 